\title{
From human to humankind: Facilitating global awareness among the gifted
}

Carol N van der Westhuizen \& Jacobus G Maree

Faculty of Education, University of Pretoria, PRETORIA, 0001

\section{Introduction}

It is generally accepted that the world has become a global village. The notion of world workers constantly migrating from one country and continent to another, has become commonplace. The everchanging world impacts not only every country in the world but, indeed, every human being - including the gifted. Little wonder then that, in 1975, scholars demonstrated appreciation for the need to move beyond national concerns and to start focusing on the bigger picture; and embrace the notion of a global village and celebrate global awareness. George Parkyn said that our "very survival depends upon a new concern with the quality of human life and its relationship to the finite world we inhabit" (in Conceptual curriculum 2004:1). Since then the development of global awareness has been increasingly highlighted by a number of authors (Rogalla, 2003; Tallent-Runnels, 2007; Terry, 2008, Volk, 2007 \& 2008). Roeper (2008) said the term global awareness "is too limiting - it is really Universal Awareness with which we are concerned". Sheard (2008) concluded that children who have lived "outside their passport countries" (third culture kids, or TCKs), could be a resource to the gifted community through the lessons the TCKs have learned. She also said that "instilling global awareness in gifted children might have social and emotional costs as well as benefits".

Over the past decade or so, the world has moved

$\begin{array}{lll}\text { From: } & & \text { To: } \\ \text { industry } & \rightarrow & \text { information } \\ \text { individualism } & \rightarrow & \text { teams } \\ \text { the electromechanical } & \rightarrow & \text { the electronic } \\ \text { competition } & \rightarrow & \text { cooperation/collaboration } \\ \text { national } & \rightarrow & \text { actively working in communities } \\ \text { industrialisation } & \rightarrow & \text { digitalisation } \\ \text { urbanisation } & \rightarrow & \text { globalisation } \\ \text { immigration } & \rightarrow & \text { world workers } \\ \text { management } & \rightarrow & \text { networking (Savickas, 2006) }\end{array}$


It is critically important to keep these changes in mind when reading this article. Understandably, different scholars emphasize different moderators of the notion of global awareness. We will now focus on some of these facets. (See: Figure 1)

\section{Different moderators of global awareness}

\section{Critical thinking}

Gibson, Rimmington, and Landwehr-Brown (2008) emphasized the value of critical thinking and global awareness to sensitize students to the beliefs and values of other cultures in order to enhance their global-learning interactions. Reflection, meta-cognition and intrapersonal intelligence are regarded by Gibson et al. (2008) as "critical for the achievement of the global-learning goal".

Utopian thought, the vision of an ideal society is useful when combined with critical thinking that can "cut through ... idealistic pictures of the best possible society" (Ambrose, 2008). Gifted students need to be guided in "grappling" with their utopian visions and reality, and students can also focus on their ideal self as opposed to their real self (Theunissen in Ambrose 2008). Ambrose (2008) cautioned that it is important to "capitalize on the powerful thought capacities" of the gifted to help them differentiate between "dogmatic utopian frameworks and responsible optimism based on imaginative idealism modified by pragmatic problem-solving" (Gibson, et al. 2008). In other words, it is essential for the gifted to be realistic in their idealism. After all, we live in an imperfect world that seems to be becoming more imperfect as we make our way through the $21^{\text {st }}$ century.

\section{A dynamic problem-solving attitude (or a focus on solutions)}

Gifted learners are morally sensitive and concerned about the future (Silverman, and Passow, in TallentRunnels 2007) and they could therefore be helped to cope with problems and even be enabled to change the future (Torrance, in Tallent-Runnels 2007), while they consider "possible, probably and preferable futures" (Passow, in Tallent-Runnels 2007). We would like to suggest that, in changing circumstances, such as those currently being experienced in our own country of South Africa, timely intervention with the gifted can significantly improve their ability to better deal with change, adapt to and cope with changing surroundings ... to exercise wisdom and to impact on the common good globally (Sternberg, 1999, 2001). In this way, perhaps, we could move closer to meeting the need for "creative productive leaders who will engage in dynamic problem-solving at all levels ..." (Eriksson, 1993).

\section{A caring attitude, commitment and compassion}

The dream of (Passow and Shiff, 1989) developing caring, concerned, compassionate, committed individuals, who hold a passion for the common good, deserves to become a facet of learning programs for every gifted student. Investigation of the most serious world problems needs to appear in programs 
developed specifically for the gifted, who, as a result of their idiosyncratic configuration of character traits, occupy the inside track toward understanding and devising possible handling mechanisms. Further, it is the right of every gifted student to be acquainted with emotional intelligence, the emotional, personal, social and survival dimensions of intelligence, which increases our success in dealing with environmental demands (Bar-On, 2003).

\section{Acceptance of global interdependence}

Global interdependence presents the perfect opportunity for the gifted to develop global awareness and become responsible citizens of the world Gibson, et al. 2008. They drew attention to interdependence, climate change, interconnectedness via the Internet, news and communication systems, including mobile communication and cultural diversity due to migration and high volumes of air travel as globalization effects, which impact on the classroom and the workplace. Gifted individuals, known for their individuality in a sense, almost by default, are propelled into the 'limelight', where they discover hitherto undeveloped strengths and more often than not, prove themselves to be exceptionally dependable societal assets.

\section{Utilizing the humanities in the classroom}

Sisk (2002) said the use of the humanities in the classroom is an ideal conduit to facilitate appropriate, future-oriented educational experiences for the gifted and asserted that humanity can move forward in appropriate fashion only if it takes cognizance of and builds on the past: "As they explore the record of humankind in the world, gifted and talented students will be able to develop a concept of the future as an infinite array of possibilities" (Sisk, 2002). This view complements the view expressed by Passow, who claimed that: "If we are to know where we are going, we must know where we have been". The aim in utilizing the humanities is to "integrate, to synthesize and to evaluate that which is, and that which could be ... to bring the humanities back into greater prominence in education, particularly for the gifted and talented students" (Sisk, 2002). Sisk continued: "Gifted and talented students have the potential to be the creative developers and refiners, the analyzers and synthesizers of the patterns in life, and most important, they have the potential to be the forward thinking proposers of better alternative 'futures' and 'presents' in the interests of oneself and others". Examples of the way in which the humanities can be utilized to facilitate future-oriented educational experiences for the gifted include the following. Sisk (2002) described the effectiveness of the Diversified Educational Experiences Program (Project DEEP) with an emphasis on the student evaluation of completed projects, Project Mythic Journey, an exploration by talented students of the "natural interrelationship of intellectual, social, spiritual and aesthetic human endeavors", and the Global Village, an examination of historical events and a consideration of ways to prevent "war and failure in human relationships". A sample lesson in the Global Village-book published in 1989 is: "South Africa: Struggle for equality". 


\section{Teaching futurism}

The gifted are typically "more interested in confronting new frontiers than in consolidating old ones" (Volk, 2008). It therefore comes as no surprise that Tannenbaum (in Volk, 2008) advocated futurism as an area of school study as early as 1983, a phenomenon which, according to Casinader (in Volk, 2008), could encourage the ability to foresee future problems and to try to prevent them. Jenkins (in Volk, 2008) also emphasized the link between futures education and the "development of a global outlook" (Volk, 2008), noting that the focus of thinking needs to move from present to future, because "the context of the years 2010-2050, years in which today's students will be living and working", is not sufficiently addressed in schools. A number of programmes that are aimed at facilitating global awareness among the gifted will now be highlighted.

\section{Global awareness programmes}

\section{Programs to moderate spiritual awareness among the gifted}

Observation of the typical search for deeper meaning in life among the gifted has led to the expansion of global awareness to include spiritual intelligence (SQ), defined by Sisk \& Torrance as "the capacity to use a multi-sensory approach - including intuition, meditation, and visualization - to access one's inner knowledge, in order to solve problems of a global nature" Sisk (2008). Palmer (2002) rightfully maintained that we "miss the mark in education if we separate the cognitive and the affective realms not only in the lives of students, but among faculty as well ... Spirituality is about our ultimate understanding of what is real in our lives. It is about exploring the larger questions of life". Palmer said that students "who get involved in service probably have a greater tendency to raise spiritual questions ... Getting students involved in an active life of citizenship and service is a powerful way to generate reflection, especially if it is linked with personal mentoring" (Gibson et al. 2008).

\section{Programs to facilitate service learning}

Numerous authors Terry, Bohnenberger, Renzulli,\& Cramond, (2008); \& Sisk, 2008; Rogalla, 2003; described the value of service learning initiatives to promote the development of co-cognitive factors in the gifted to enable and encourage them to respond to community needs in socially constructive ways. Terry (2008) recommended the use of the highest level of service learning, i.e. community action, which "involves a high degree of service, producing a broader community impact and the highest degree of learning", "making it ideal for involvement by gifted students ... we must offer them opportunities to develop socially, morally, and ethically” (Terry 2008 Tallent-Runnels 2007). 


\section{The Earth Force service-learning program}

In the Earth Force service-learning program which is integrated into the science or social studies curriculum, students develop their sense of self "to form values that will shape their lives as adult citizens" (Sisk, 2008). The Future Kids Global Awareness Institute offers students an opportunity to explore world issues through interactive simulations and curricular materials to empower and enlighten them and to motivate them to make a difference by supporting a cause (Global Awareness Institute, 2007).

\section{The Future Problem Solving Program (FPSP)}

FPSP, one of the best-known and widely acclaimed service learning programs, is a 35 year-old, six-step program begun by Torrance in 1974, and which now reaches 250,000 students in at least five countries through 43 affiliated programs (Rogalla, 2003). The main objective of FPSP is teaching students how to think, and its major foci are creative problem solving and futuristic issues, which help students "adapt to a changing world and shape the future", while implementing proposed solutions through the Community Problem Solving Component (CmPS) (Rogalla 2008).

Renzulli and Cramond (in Terry, et al. 2008) advocated service learning initiatives such as the community problem-solving component in the Future Problem Solving Program (International) (FPSPI) and Terry and Bohnenberger (in Terry et al. 2008) recommended the use of the highest level of service learning, i.e. community action, as the ideal avenue for helping gifted students solve community problems creatively in a socially constructive way.

\section{The Texas Honors Leadership Program (THLP)}

Programs that seek to raise global awareness among gifted students include the Texas Honors Leadership Program (THLP), which focuses on using SQ to build global awareness. Students study the lives of spiritual pathfinders like. Martin Luther King, Mother Theresa and Nelson Mandela and the program applies Kidder's (1999) ends-based, rules-based and care-based principles to moral dilemmas (Sisk, 2008). These THLP students once raised money to send rabbits and chickens to the poor through the Heifer International Program in a "global outreach".

\section{Networks}

Besides global awareness programs networks such as the Global Awareness Network have been established to "respond to the concerns of the gifted and talented about the future and the world they live in by giving them opportunities to grow in understanding of different cultures and global interdependence and to provide them with the tools and experience to participate in the shaping of their destinies" (Children's Global Awareness Corner, (2009). The proliferation of conferences such as the 
AGATE Conference with themes like "A world of promise: Gifted students as global citizens" (AGATE Conference Announcements, 2009) provide an ideal platform to facilitate networking among the gifted and provide evidence of the high premium placed on the development of global awareness among the gifted. We will now focus on the role of teachers, who represent a key ingredient in any and every programme aimed at facilitating global awareness among the gifted.

\section{Intervention strategies: Involving teachers in facilitating global awareness}

'Cultural capital', or people's perceptions of their environment must be taken into account when any intervention program is planned (Hernes, 2002). The school, community infrastructure and management have a major impact on the effectiveness of any intervention program.

Passow and Schiff (1989) proposed the following six broad areas in which intervention with the gifted could take place:

- involving the gifted in strategies to facilitate peace and disarmament and developing social conscience and a sense of social responsibility;

- $\quad$ prompting them to consider what the future holds a view supported by (Necka, 1989)

- encouraging them to question the morality and ethicality of subject areas, and not to shy away from asking conscience questions about the contents of subject areas;

- motivating them to engage actively in studying to solve real-life challenges;

- guiding them to read about, scan and engage in critical discussions about news media intelligently and on a regular basis; and,

- facilitating networking opportunities for the gifted, both nationally and internationally.

Peterson (1997) said that teachers find it difficult to distinguish between the outward appearances and behavior of gifted students and their true potential, mostly because "they do not share personal information readily. Their life experiences may not have given them the vocabulary, intellectual enrichment, social experiences, or modeling of behavior ... they may, in fact, be sullen and withdrawn, hostile, and sensitive to slights - trained thoroughly by adults who disappoint. They may initially be difficult to work with". Peterson stressed the need for a flexible, accommodating approach to identify the "toughest at-risk" students' deeper-seated needs and strengths.

Ford and Harmon (2001) said that it is essential to educate teachers with regard to diversity education and proposed that teachers be trained with regard to:

- engaging in critical self-examination to explore their attitudes and perceptions with regard to cultural diversity, and, especially, the possible impact of these aspects on learners' educational opportunities and achievements;

- acquisition and use of accurate information with regard to cultural diversity and using this information to inform their own learning facilitation; 
- learning how to infuse their insights regarding diversity and perspectives into classroom practice; and

- networking with a variety of groups, including parents, communities and organizations.

\section{FIGURE 1 HERE}

\section{Conclusion}

In light of the "tragic gap" between reality and possibility, which is, essentially the tension between "what's really going on around us, the hard conditions in which our lives are currently immersed, and what we know to be possible from our own experience" Palmer, 2009). It is necessary to reflect on the extent to which education systems and programs for the gifted "world-wide are preparing students to think beyond national boundaries, and to see problems in an international context" (Volk, 2007). The implementation of FPS needs to be adapted for implementation in different countries and "the situation in South Africa is a clear example of how FPS needs to be conceived in different ways in different countries if it is to be accepted" (Volk, 2007). In addition, global-learning curricula "require the creation of a set of conditions that demand the integration of a number of processes and attributes along with the use of technology to facilitate global connections to educate the future world citizen" (Gibson, et al. 2008). Perennial problems that hinder the effective preparation of gifted students as world citizens and leaders, are the lack of attention to identification of the gifted, and failure to set "priorities within intervention" for gifted students (Van Tassel-Baska in Gibson et al. 2008).

Battling the poverty cycle, escalating socio-economic deprivation, lack of education, joblessness, and spiralling crime levels, require vision and wisdom ... from all concerned. Although globalization is regarded as the key to motivating reforms "in diverse spheres of action ... the concept has not yet been adequately translated into action" (Volk, 2008). This manifests in the lack of concrete examples of ways in which educators internationalize the curriculum in a "tangible and easy replicable way" (Eisenchlas \& Trevaskes in Volk, 2008), and thus the link between futures education and developing a "global outlook" is neglected.

It does seem, however, that FPSP has succeeded to an extent in broadening the perspectives of the 250,000 annual participants who see the world globally, they have "moved beyond the limitations of their immediate environments ... and now see themselves as citizens of a global world" (Volk, 2008). “That's one thing I've learned through doing FPSP - that we're all part of one world. And it's not so big, either" (student cited in Volk, 2008).

In conclusion, gifted children should be channeled into special education programs to facilitate global awareness as soon as they can be effectively identified (Bar-On \& Maree, 2009). Gifted education 
should be regarded as special education (Van der Westhuizen \& Maree, 2006) as it is in Canada, as well as in a growing number of other countries around the world. These programs need to become globally aware as early as possible so that the gifted can learn and develop together, without running the risk of experiencing feelings of social isolation, boredom and low self-esteem that often lead to underachievement (Reis \& Renzulli, 2004; Robinson, 2002; Seevers \& Shaughnessy, 2003; Sisk, 2002; Swiatek, 1995).

Last, the authors, both previously African delegates to the World Council for Gifted and Talented Children the wish to invite the reader to spend a few more minutes while we pose the following questions for further discussion:

- We are indebted to the editor of this guest issue for the opportunity to share a platform with scholars throughout the world. This endeavor will however, remain incomplete, unless it yields tangible results. Regrettably, the gifted in Africa are not remotely receiving a 'fair deal'. Where do we start? Who will take the lead and facilitate collaboration between scholars from our continent and a network of scholars with a keen interest in the field of the gifted disadvantaged to set up working groups and facilitate exchange schemes including visiting professors, exchange students, etc.

- How should we facilitate an international study to investigate the comparative experiences of the gifted disadvantaged throughout the world?

- How can we collectively create national, continental, international and transnational awareness of the particular needs of the gifted in Africa to enhance global awareness world-wide?

- What are the possibilities for arranging an international conference on this theme somewhere on the African continent? 


\section{References}

AGATE Conference Announcements. (2009). Pp 1-3. Available online: http://fagatenyo.ipower.com/welcome.html Accessed 12 September 2009

Ambrose, D. (2008). Utopian visions: Promise and pitfalls in the global awareness of the gifted. Roeper Review, 30, 52-60.

BarOn, R. (2003). How important is it to educate people to be emotionally and socially intelligent, and can it be done? Perspectives in Education, 21(4), 3-16.

Bar-On, R., \& Maree, J.G. (2009). In search of emotional-social giftedness: A potentially viable and valuable concept. In Larisa V. Shavinina (Ed.) The handbook on giftedness. New London: Springer Science.

Children's Global Awareness Corner. (Sa). Available online: http://www.jsca.org/docs/Global.htm Accessed on: 12 September 2009 Conceptual curriculum. (2004). George Parkyn National Centre for Gifted Education. Pp 1-6. Available online: http://www.georgeparkyncentre.org.cc.html Accessed 12 September 2009

Eriksson, G.I. (1993). The global village beyond 2000: Networking with the gifted disadvantaged. In Wallace, B. and Adams, H.B. (eds.). Worldwide perspectives on the gifted disadvantaged, (pp. 100-132).. Bicester, Oxon.

Ford, D.Y. and Harmon, D.A. (2001). Equity and excellence: Providing access to gifted education for culturally diverse students. Journal of Secondary Gifted Education, 12(3), 141-150. [Online serial]. URL

http://infotrac.galegroup.com/itw/infomar...69anddyn=5!xm-57-0-A73842269?sw-aep=up-itw. Accessed 18 September 2009

Gibson, K.L., Rimmington, G.M. \& Landwehr-Brown, M. (2008). Developing global awareness and responsible world citizenship with global learning. Roeper Review, 30:11-23.

Global Awareness Institute. (2007). Stop the genocide: Save Darfur! Available online: http://futurekids.org/id29.html Accessed 12 September 2009

Hernes, G. (2002). UNESCO vs HIV/AIDS. The history and ten lessons. Perspectives in Education, 20(2), 115-120.

Palmer, P. (2009). Ground on which to stand as things fall apart. Interviewed by Bill Moyers. Reprinted from Bill Moyer's journal. Available online; http://carolynbaker.net/site 
Palmer, P. (2002). One year later: Exploring the large questions of learning and life after September 11: An interview by John Dalton. NASPA Journal of College and Character, 1-5. Available online: http://www.collegevalues.org/articles.cfm?a=1\&id=989 Accessed 13 September 2009

Parkyn, Q. (2004), Conceptual curriculum. National center forGifted Ed.

Passow, A.H. and Schiff, J.H. (1989). Educating gifted persons who are caring and concerned. Gifted Education International, 6, 5-7.

Peterson, J.S. (1997). Bright, tough, and resilient - and not in a gifted program. Journal of Secondary Gifted Education, 97(8), 121-137. [Online serial]. URL http://weblinks2.epnet.com/citation.asp?t... $+\mathrm{ri}+\mathrm{KAAACB} 1 \mathrm{D} 00027568+\mathrm{sm}+\mathrm{ES}+14 \mathrm{~B} 9 \mathrm{andfn}=1$ andm $=3$ [1-16]

Reis, S.M., \& Renzulli, J.S. (2004). Current research on the social and emotional development of gifted and talented students: Good news and future possibilities. Psychology in the Schools, 41, published online in Wiley InterScience (http://www.interscience.wiley.com). Accessed 17 September 2009.

Robinson, N.M. (2002). Introduction. In M. Neihart, S.M. Reis, N.M. Robinson, \& S.M. Moon (Eds.), The social and emotional development of gifted children. Waco, Texas: Prufrock Press Inc.

Roeper, A. (2008). Global awareness and gifted children: Its joy and its history. Roeper Review, 30:8-10. Rogalla, M. 2003. Future problem solving program. NEAG Center for Gifted Education and Talent Development, Newsletter. $\quad$ Spring: 1-6. Available online: http://www.gifted.uconn.edu/nrcgt/newsletter/spring03/sprng032.html Accessed 13 September 2009

Seevers, R., \& Shaughnessy, M. (2003). Reflective conversation with Dorothy Sisk. Gifted Education International, 17 (1), 16-41.

Sheard, W. (2008). Lessons from our kissing cousins: Third culture kids and gifted children. Roeper Review, 30, 31-38.

Savickas, M.L. (2006). Counselling for Career Construction (Facilitating the Storied Approach in (Career) Counselling: Practical Implementation). 15th Australian Career Counselling Conference, Sydney: 18 April 2006.

Sisk, D. (2002). Spiritual intelligence: The tenth intelligence that integrates all other intelligences. Gifted Education International, 16 (3), 208. 
Sisk, D. (2008). Engaging the spiritual awareness of gifted students to build global awareness in the classroom. Roeper Review, 30:24-30.

Sisk,D. (2002). The place of the humanities in the gifted program, Available online: dept.lamar.edu/.../The\%20Place\%20of\%the20\%HUMANTIES\%20in $\% 20$ the $\% 20$ Accessed Teтpo, 22 (2) 4-5 12 September 2009.

Sternberg, R.J. (1999). The theory of successful intelligence. Review of General Psychology, 3, 292-316.

Sternberg, R.J. (2001). Wisdom and education. Perspectives in Education, 19(4), 1-16.

Swiatek, M.A. (1995). An empirical investigation of the social coping strategies used by gifted adolescents. Gifted Child Quarterly, 39, 154-160.

Tallent-Runnels, M.K. (2007). Resources for gifted students studying the future. Gifted Child Today, Winter, 30(1), 50-54.

Terry, A.W. (2008). Student voices, global echoes: Service learning and the gifted. Roeper Review, 30, $45-51$.

Terry, A.W., Bohnenberger, J.E., Renzulli, J.S., Cramond, B. \& Sisk, D. (2008). Vision with action: Developing sensitivity to special concerns in gifted youth. Roeper Review, : 30, 1-67.

Van der Westhuizen, C., \& Maree, J.G. (2006). Some thoughts on the training of teachers of gifted learners. Gifted Education International, 21 (2/3), 201-217.

Volk, V. (2007). Citizens of the future world: International outreach in the Future Problem Solving Program. Creative Learning Today, 15(2), 4-10.

Volk, V. (2008). A global village is a small world. Roeper Review, 30, 39-44. 